De todo o exposto, podem ser fixadas conclusões.

Dentro da função genérica do transporte, cada tipo tem sua função específica. Embora concorram entre si, em muitos casos, são complementares uns dos outros e podem e devem, por isto, ser coordenados, para proveito geral da economia nacional, como da universal.

A ferrovia, o transporte marítimo e o aéreo oferecem grande regularidade, enquanto o rodoviário é o que menor índice de regularidade apresenta. Quanto a velocidade, depois do avião, a ferrovia é a de maior índice, máxime nas longas distâncias (basta pensar que o automóvel é forçado a parar longas horas por dia) e o transporte flu-
vial o de menor gráu.

Quanto à comodidade, o automóvel a todos supera pelas suas características de adaptação e mobilidade. Quanto a custo: o avião, o automóvel para longas distâncias, o trem para pequenas, o transporte fluvial e o marítimo se apresentam em ordem decrescente.

Fácil será depreender as inúmeras combinações possíveis entre êstes vários sistemas - o que não tem faltado de se verificar, quer espontâneamente, por entendimentos (cartéis, ententes, etc.), entre êles, quer sob a iniciativa do Poder Público. Cremos, aliás, que êste é um a setores em que mais se verifica - e progressivamente ocorre a intervenção do Estado na Economia, sob inúmeras modalidades.

E' que a função econômica do transporte aparece como fundamental e exerce influência decisiva sôbre todos os setores e aspectos da vida econômica. As características de muitos dos sistemas estudados, particularmente o ferroviário, o marítimo e o aéreo, conduzem naturalmente à concentração, fato quase universalmente observado. Isto fàcilmente se explica porque quanto maiores as zonas observado. Isto facilmente se explica porque quanto maiores as zonas atendidas, quanto mais variados seus produtos, maiores vantagens se oferecem ao transporte, em sua economia interna e na elaboração de suas tarifas. Mostramos, doutra parte, que, principalmente no tr. ferroviário, domina a característica da pluralidade de fretes, isto é, a multiplicidade de preços em categorias (o que se observa também no transporte de pessoas) - e êste é um traço específico dos preços de monopólio. Daí, portanto, por diversos motivos de ordem econômica, se haver chegado às mais altas formas de concentração e de cartelização ou trustificação nos vários gêneros de transporte.

Sempre que isto ocorre, natural e necessária é a intervenção do Poder Público, em qualquer das múltiplas formas que se registram, atualmente, nos vários países do mundo, para a defesa da economia e dos interêsses da coletividade, para a proteção do bem comum, em uma palavra. E nada melhor do que isto sublinha a transcendência da função
econômica do transporte.

\section{OS IMÓVEIS SITUADOS NO URUGUAI E A EXTRATERRITORIALIDADE DO ESTATUTO BRASILEIRO REFERENTE AO REGIME DE BENS NO CASAMENTO}

\author{
Camillo Martins Costa
}

\section{EXPOSIÇÃO}

Marido e mulher brasileiros, casados, no Brasil, na vigência do Código Civil, sem contrato antenupcial, querem, agora, desquitar-se. O casamento se realizou antes de 1942. Ambos os nubentes eram domiciliados no Brasil, onde também se fixou o domínio conjugal. Não ocorreu qualquer dos motivos indicados no $\$$ único do art. ${ }^{\circ} 258$ do Código Civil como determinantes do regime de separação obrigatória. Antes do casamento, o marido adquirira, por herança materna, um imóvel situado na República do Uruguai. Pretende êle que tal imóvel representa patrimônio seu, particular, isto é, não compreendido no patrimônio do casal, e que, assim, na partilha, referente ao projetado desquite, não entrará o aludido imóvel. Posto isso,

\section{PERGUNTA-SE:}

$1^{\circ}{ }^{\circ}$ É ou não o regime da comunhão universal de bens que prevalece nesse casamento?

2. ${ }^{\circ}$ ) No caso afirmativo, - êsse imóvel do Uruguai estará, porventura, excluído da comunhão?

$3 .^{\circ}$ ) Se o imóvel não está excluído na comunhão, haverá, para a mulher, alguma dificuldade no sentido de tornar efetivo o seu direito de incluí-lo na partilha?

$4^{\circ} .^{\circ}$ No caso de existir alguma dificuldade a êsse respeito de que modo se poderia proceder para obviá-la? 


\section{PARECER}

I. Entedemos que o regime de bens, que se estabeleceu, foi o da comunhão universal, já que ambos os cônjuges eram brasileiros nada estipularam acêrca de relações patrimoniais, sendo certo, também, que nada ocorreu de natureza a impor o regime de separação, nos têrmos do $\S$ único do art. $^{\circ} 258$ do Código Civil Brasileiro. Instituiu-se, portanto, a comunhão universal, que é o regime legal decorrente da regra exarada no dito art. ${ }^{\circ} 258$, regra essa que se aplica ao caso por fôrça do preceito do art. ${ }^{\circ} 8 .^{\circ}$ da primitiva Lei de Introdução ao Código Civil, assim enunciado:

"A lei nacional da pessoa determina a capacidade civil, os direitos de família, as relações pessoais dos cônjuges e o regime de bens no casamento, sendo lícito quanto a êste a opção pela lei brasileira".

Como se vê, a nossa Lei de Introdução, vigente ao tempo da celebração do casamento, ocorrido antes de 1942, incluía o regime de bens entre as relações jurídicas dominadas pelo estatuto nacional da pessoa. Na espécie, ambas as pessoas eram brasileiras; e, aliás, para o efeito, bastaria que o fôsse apenas o marido. Sendo assim, as relações patrimoniais dos cônjuges se estabeleceram pelo estatuto pessoal, isto é, pela lei brasileira, segundo a qual o regime da comunhão é o que prevalece quando não há contrato e quando não ocorre nenhum dos fatos que tornam obrigatória a separação. Fixado tal regime, tornou-se êle definitivo e imutável por efeito do princípio da irrevogabilidade, consagrado pelo art. ${ }^{\circ} 230$ do Código Civil. Aliás, mesmo que o casamento se tivesse realizado na vigência da nova Lei de Introdução do Código Civil (decreto-lei n. ${ }^{\circ} 4.657$, de 7 de setembro de 1942) outro não seria o regime de bens referente aos cônjuges aludidos na consulta. E' exato que por essa nova lei $\left(\operatorname{art}^{\circ}{ }^{\circ} .^{\circ} \S 4 .^{\circ}\right)$, o estatuto pessoal, até então prevalente em matéria de regime patrimonial dos cônjuges, fo substituído, no Brasil, pelo estatuto do primeiro domicílio conjugal. Mas, se é certo que, no caso, os nubentes eram domiciliados no Brasil, onde se casaram e onde continuaram domiciliados, conclui-se que, mesmo a teor do aludido art. $0^{\circ} 7 \S 4 .^{\circ}$ da Nova Lei de Introdução, o estatuto brasileiro teria dominado o regime patrimonial. A verdade, porém, é que êsse regime se estabeleceu nos têrmos do direito brasileiro, por fôrça do estatuto nacional, que êsse mesmo direito impôs no art. $^{\circ} 8 .^{\circ}$ da primitiva Lei de Introdução. Tal regime que, aliás, em espécie não se alterou, é o da comunhão universal de bens.

II. Como se vê da exposição, o marido, antes de casar, herdou um imóvel situado no Uruguai. Segundo se despreende, não se trata de sucessão testamentária, ficando, pois, excluída, para os efeitos dêste pa- recer, a hipótese de que o imóvel esteja clausulado de incomunicabilidade ou de que esteja prêso a algum fideicomisso. Assim sendo, êsse imóvel, por fôrça do regime da comunhão universal, estabelecido no caso, entrou para o patrimônio do casal.

Prevemos, entretanto, a objeção decorrente do art. $^{\circ} 10 .^{\circ}$ da Lei de Introdução ao nosso Código Civil (a primitiva), a mesma a que pertence o art. ${ }^{\circ} 8 .^{\circ}$ acima invocado.

Dispõe o art. $^{\circ} 100^{\circ}$ :

"Os bens móveis ou imóveis estão sob a lei do lugar onde situados, ficando, porém, sob a lei pessoal do proprietário os móveis de seu uso pessoal ou os que êle consigo tiver sempre, bem como os destinados a transporte para outros lugares".

Dir-se-á que, se o art. $.^{\circ} 10 .^{\circ}$ submete os bens móveis ou imóveis à lei da sua situação (estatuto real), - é a lei do Uruguai, e não a brasileira, que deve ser observada, em tôdas as relações jurídicas referentes ao imóvel em questão, isto é, ao imóvel que o marido, figurado na consulta, herdou na vizinha República, antes do casamento. Assim, as relações patrimoniais dos cônjuges, no que se referem a êsse imóvel, estariam regidas pela lei oriental, o que vale dizer - regular-se-iam pelo art. $^{\circ} 1951$ e 1964 do Código Civil Uruguaio, artigos por fôrça dos quais o mesmo imóvel se considera "capital marital" e não se inclui na comunhão resultante da sociedade legal estabelecida pelo fato do casamento (art. $\left.{ }^{\circ} 1950\right)$.

\section{Reza o art. 1951:}

"Son bienes proprios de la mujer los que constituyen la dote y del marido los que componem el capital marital".

Dispốe o art. 1964:

"Se reputará gananciales todos los biens existentes en poder de cualquiera de los conjuges al tiempo de disolverse la sociedad, si no se prueba que pertenecian privativamente al marido ó á la mujer, á la celebracion del matrimonio ó que los adquirió después por herencia legado ó donacion".

Mas, a verdade é que a regra de direito internacional privado, expressa pelo art. ${ }^{\circ} 100^{\circ}$ do nosso Código Civil, não tem alcance de fazer prevalecer, relativamente ao dito imóvel, situado no Estado Orien- 
tal, o regime matrimonial de bens, adotado pela legislação uruguaia. E. que, segundo a exata inteligência dêsse art. ${ }^{\circ} 100^{\circ}$, os móveis ou imóveis só estão submetidos ao estatuto real (lei da situação) enquanto considerados isoladamente, isto é, uti singuli, como objeto imediato do direito de propriedade. Quando, porém, algum de tais bens, embora apareça numa relação jurídica, nela figura como elemento secundário ou indireto, ou seja como parte integrante de uma universalidade, criada sob a precípua influência de interêsses e direitos pessoais, - êle não atrai para essa relação jurídica o estatuto real.

Assim, por exemplo, quando se perquire qual o estatuto que deve dominar uma sucessão hereditária ou o regime patrimonial de um casamento, não se cogita da natureza dos bens existentes em qualquer dessas universalidades, mas, sim, da índole destas últimas e de certas circuhstâncias de expressão estritamente pessoal. Clóvis Beviláqua - "Código Civil", vol. 1. ${ }^{\circ}$, pág. 130; Rodrigo Otávio - "Manual do Código Civil de Paulo de Lacerda" - vol. 1.०, parte 2.a n. no 320 pág. 302; Eduardo Espínola e Eduardo Espínola Filho "Tratado de Direito Civil Brasileiro" - vol. VIII, parte especial, tomo 2..$^{\circ}$, págs. 640 e 641; Carvalho Santos - Código Civil Interpretado" - vol. I, pág. 143).

$\mathrm{O}$ art. $^{\circ} 8 .^{\circ}$ da nossa primitiva Lei de Introdução, ao determinar que o regime de bens no casamento, na ausência de pacto, é regulado pela lei nacional da pessoa consorciada (isto é, do marido), indicou um estatuto único e universal para todos os bens, seja qual fôr o lugar da sua situação. $O$ estatuto real, de que fala o art. ${ }^{\circ} 10 .^{\circ}$ relativamente aos bens móveis ou imóveis, não prevalece contra a regra do art. ${ }^{\circ}$ 8. Esta sobreleva e predomina, não só porque é referente a uma universalidade, como porque rege situações jurídicas não suscetíveis de divisão ou fracionamento. A unidade do casamento postula um estatuto único para as relações pessoais e patrimoniais dos cônjuges. Repugna admitir que, em razão da situação dos bens trazidos para o casamento ou adquiridos durante êle, se imponham, para tais bens, regimes matrimoniais diferentes.

O que vai aqui resumidamente exposto, são os princípios do direito brasileiro concernentes ao assunto, princípios que, aliás, não discrepam dos consagrados, quanto à matéria, pelo Código Bustamantete, e já, anteriormente, pela Conferência de Haya.

III. Infelizmente, tais princípios, pôsto sejam os melhores, não são pacíficos em doutrina, e nem sempre foram acolhidos nas leis civis dos diferentes países. O Código Civil do Uruguai, por exemplo, que é de 1868, assim dispõe no seu art. $^{\circ} 5^{\circ}$ :
"Los bienes raices situados en la Republica son" exclusivamente regidos por las leys orientales, aunque sus dueños sean extrajeros y no residan en el pais".

Note-se o rigor com que aí se consagra o estatuto real para os imóvéis situados no país. Por êsse art. ${ }^{\circ} 5^{\circ}$, a submissão de tais bens à lei da situação corresponde a uma regra quase absoluta, em face da "qual não cabe distinguir entre os imóveis encarados uti singuli e os considerados uti universitas.

Todos êles, a teor do art. ${ }^{\circ} .^{\circ}$, ficaram "exclusivamente" regidos pela lei oriental. Neste advérbio "exclusivamente", o legislador de 1868 exprimiu tôda a intransigência da sua adesão à escola estatutária.

Isto, evidentemente, não significa que, para os imóveis situados no Estado Oriental, deva, obrigatòriamente, prevalecer, como regime matrimonial de bens, o tipo "gananciales", definido, como regime legal, nos art. ${ }^{\circ} 130$ e 1.950 e seguintes daquele Código Civil.

O legislador uruguaio, no art. ${ }^{\circ} 1.938$, permitiu as convenções especiais, admitindo que elas se afastassem do tipo geral, respeitados, naturalmente, os bons costumes e certas restrições de ordem pública, que outras não são, pelo menos quanto ao fundo, além das apóntadas nos art. ${ }^{\circ}$ s 1.939 e 1.940 . Daí os enunciados seguintes:

"La ley, sólo á falta de convenciones especiales, rige la asociación conjugal en cuanto á los bienes" (art. ${ }^{\circ} 1.938$ in fine).

"Á falta de estipulaciones especiales que modifiquen la sociedad conjugal, las reglas establecidas en el capitulo seguiente formaran el derecho comum de la Republica" (art. $\left.{ }^{\circ} 1.941\right)$.

Claro está, portanto, que o citado art. $^{\circ} 55^{\circ}$, no que diz respeito aos regimes matrimoniais referentes a imóveis situados no paỉs, não exclui os regimes resultantes de convenção especial, desde que lícita. Tais imóveis, por serem regidos exclusivamente pelas leis orientais, não estão submetidos, necessàriamente, ao regime legal uruguaio (ganaciales), e, sim, a qualquer regime decorrente de expressa convenção, desde que admitido pelas leis daquela República.

Parece evidente que, se o legislador de 1868, nos citados art. ${ }^{\circ} \mathrm{s}$ 1.938 e 1.941, se referiu a "convenciones", e ainda restringiu o conceito por fôrça do adjetivo "especiales", - não teve em mira permitir que também os regimes estrangeiros, resultantes da falta de qualquer pacto antenupcial, pudessem prevalecer sôbre o da lei uruguaia.

Não vamos discutir se a aplicação supletiva dos chamados regimes legais se funda, ou não, na vontade presumida dos cônjuges, ponto êste sôbre o qual, como se sabe, há sérias divergências entre os doutrinadores. Mas, concedendo, mesmo, que o fundamento daquela 
aplicação supletiva seja a presunção de um pacto tácito, nem assim se poderia enxergar, nesse pacto, $\mathrm{o}$ atributo exigido pelos ditos art. ${ }^{\mathrm{s}} \mathrm{s}$ 1.938 e 1.941. Por isto que é tácito e resulta de uma vontade presumida, difícil seria enquadrar aquêle na categoria das "convenções especiais", que outras não serão senão as resultantes de manifestação expressa.

O único dispositivo do Código Uruguaio, que permite a extraterritorialidade de estatutos legais estrangeiros, em tema de regimes matrimoniais de bens, é o do art. ${ }^{\circ} 130$; mas êste só o faz sob a condição de que os cônjuges, tendo casado no estrangeiro, hajam fixado domićlio no território do Uruguai.

Eis o preceito do art. 130 :

"Los que se hayan casado en pais extrangero, y "passaren á domiciliarse em la Republica, se miraran como separados de bienes, siempre que, en conformidad á las leys bajo cuyo imperio se casaron, no haya habido entre ellos sociedad de bienes".

Não vem agora ao caso, para os objetivos do parecer, fixar todo o exato conteúdo dêsse art. ${ }^{\circ} 130$, o qual, como se sabe, foi transplantado do Código Civil Chileno com as mesmas obscuridades originais e com a mesma larga margem para controvérsias de interpretação. Uma cousa, porém, é clara: é que o dispositivo pressupôs cônjuges que viessem fixar o seu primeiro domicílio no Estado Oriental. Para êstes, não há dúvida que o art. ${ }^{\circ} 130$, pelo menos em certas circunstâncias, admitiu a extraterritorialidade dos regimes legais sob os quais, no estrangeiro, êles contraíram casamento.

Outro tanto, porém, não se pode dizer, em face do Código de 1868, relativamente aos cônjuges que instalaram fora do Uruguai o seu primeiro domicílio.

IV. No Tratado de Direito Civil Internacional, que celebrou, em 1889, no Congresso Sul-Americano de Montevidéu, o Uruguai abrandou, sensivelmente, o rigor do seu territorialismo, em tema de regimes patrimoniais no casamento. O princípio, de que os bens situados no país são regidos pelo estatuto real, não foi definido, nesse Tratado, com a mesma amplitude com que a pareceu no Código de 1868.

No Tratado, o império da lei da situação dos bens só se proclamou para as relações jurídicas, de carácter real, em que tais bens fôssem envolvidos. Nesta restrição não é difícil descobrir a influência da moderna orientação doutrinária, segundo a qual os bens só estão submetidos ao estatuto real sob o ponto de vista da sua natureza e de cada um dos atributos ligados a esta, - refugindo, porém, a êsse estatuto enquanto considerados dentro de uma universalidade jurídica, criada sob o predomínio de interêsses e de direitos pessoais.
Reza o art. $^{\circ} 26$ do Tratado de 1889 :

"Los bienes, cualquiera que sea sua naturaleza, son exclusivamente regidos por la ley del lugar donde existen en cuanto á su calidad, á su possession, á su enajenabilidad absoluta ó relativa y á todas las relaciones de caracter real de que son susceptibles".

Dispõe o art. $^{\circ} 41$ :

"En defecto de capitulaciones especiales, en todo lo que ellas no hayan previsto y en todo lo que no esté prohibido por la ley del lugar de la situación de los bienes, las relaciones de los esposos sôbre dichos bienes se rigen por la ley del domićlio conjugal que hubieren fijado de comum acuerdo, antes de la celebracion del matrimonio".

Preceitua o art. 42:

"Si no hubiessen fijado de antemano un domicilio conjugal, las mencionadas relaciones se rigen por la ley del domicilio del marido al tiempo de la celebracion del matrimonio.

No conjunto dêsses três dispositivos colhem-se duas observações de muita importância.

A primeira é a de que o estatuto da situação dos bens não impede, em regra, mesmo no tocante a tais bens, o efeito extraterritorial do regime de casamento de outro país - se êsse outro país fôr aquêle em que os nubentes, antes de casar, combinaram domiciliar-se, - ou, então (por não ter havido êsse prévio convênio), se fôr aquêle em que o marido, ao casar, estava domiciliado.

A segunda observação é a de que essa extraterritorialidade só se opera em falta de contrato especial ou nas omissões dêsse contrato, mas nunca para estabelecer regimes patrimoniais proibidos pela lei da situiação dos bens.

Verifica-se, pois, que o Tratado de Montevidéu não é infenso ao ponto de vista segundo o qual os bens, no direito internacional privado, devem, para certos efeitos, ser considerados como elementos de uma universalidade jurídica, para se submeterem ao estatuto que corresponde a esta última. Apenas, como é natural, êle não permite que tenham qualquer eficácia, no país da situação dos bens, estatutos estrangeiros proibidos pela lei dêsse país.

V. Por isto mesmo que era um diploma de carácter convencional, o referido Tratado vinculou, apenas, os países signatários, que foram 
o Uruguai, a Argentina, a Bolívia, o Paraguai e o Peru. Apesar disso, os princípios, que nêle se consagraram, foram, pouco a pouco, dominando, pelo menos no Uruguai, o direito internacional privado aplicável erga omnes, e não, sòmente, aos naturais dos Estados contratantes.

Assim, as regras do Código Civil, de 1868, se completaram com as do Tratado, recebendo dêste a influência de elementos novos, por cujo efeito bem se pode dizer que o direito uruguaio, na expressão da sua doutrina e da sua jurisprudência, moderou sensivelmente o rigor territorialista decorrente daquele velho Código.

O Professor Irureta Goyena (filho), um dos mais autorizados mestres do direito civil internacional uruguaio, ensina que o Tratado de Montevidéu, de 1889, pode ser invocado, no Estado Oriental, como doutrina corrente, incorporado ao direito dêsse país, nos têrmos do art. $^{\circ} 16$ do seu Código Civil (Curso de Sucesiones - vol. II, pág. 24).

Quem quer, pois, que, atualmente, se proponha expor ou interpretar o direito uruguaio, no tocante aos problemas da sua aplicação espacial, não poderá deixar de parte o Tratado de Montevidéu, mas, ao contrário, terá de considerá-lo vigente, não, apenas, para os naturais dos países signatários, mas para todos quantos tenham problemas daquele gênero, ao alcance da jurisdição uruguaia.

O Brasil, como se sabe, conquanto tenha tomado parte no Congresso Sul-Americano em que foi elaborado o Tratado de Montevidéu, não é signatário dêste diploma, nem a êle aderiu.

A despeito disso, e uma vez que os princípios de direito civil internacional, consagrados nesse documento, estão incorporados, como doutrina corrente, ao direito comum uruguaio, podem, sem dúvida, os brasileiros invocar tais princípios, sempre que tenham de raciocinar sôbre os problemas atinentes à eficácia da lei civil brasileira no território do Uruguai, e à eficácia da lei civil uruguaia no território do nosso país.

VI. Ponhamos, portanto, em fase do direito uruguaio, a questão de saber se dois brasileiros - casados no Brasil pelo regime legal da comunhão universal, e sempre domiciliados neste país - são, ou não, havidos, no Estado Oriental, como ligados por êsse regime, relativamente aos bens que um dos cônjuges já aí possuía por herança, ao tempo do casamento.

Já vimos (item IV, supra) qual é a fórmula dentro da qual o direito da vizinha república resolve o problema. A fórmula é esta: o estatuto domiciliar estrangeiro só prevalecerá quanto aos bens situados no Uruguai, se não envolver um regime proibido pela leï oriental.

Ora, no caso, êsse estatuto domiciliar (que é o brasileiro) impõe supletivamente o regime da comunhão universal. Cumpre, portanto, verificar se a comunhão universal de bens entre cônjuges, é, porventura, um regime proibido no Uruguai.
Segundo o testemunho do mesmo Irureta Goyena, a questão é controvertida no seu país, embora êste jurisconsulto não vacile em afirmar que a comunhão universal, como regime de casamento, absolutamente não é proibida pelas leis orientais. $\mathrm{O}$ emérito professor de Montevidéu, depois de examinar, uma por uma, as três objeções comumente levantadas contra a admissibilidade dêsse regime inclusive a que procura amparar-se no art. 1.880 , do Código de 1868 , rebate vitoriosamente tais objeções, para proclamar, como proclama, a perfeita licitude daquele.

Ora, se a comunhão universal, entre cônjuges, não é proibida no Uruguai, conclui-se que o regime legal brasileiro - quando representar o estatuto domiciliar dos nubentes, ou, ao menos, o do maridotem efeito extraterritorial, e domina, pois, os bens que qualquer dêles, antes de casar, já possuísse naquela república.

Sendo assim, a própria justiça do Uruguai, na estrita observância dos princípios de direito internacional privado do seu país, teria de considerar como pertencente à comunhão conjugal o imóvel a que se refere a consulta.

VII. Entendemos que o juiz brasileiro, na eventual contenda, deve fazer todo o possível por assegurar o império do estatuto pessoal dos cônjuges, inclusive no tocante ao imóvel situado no Uruguai.

Isso nada mais será do que cumprir a lei brasileira (art. ${ }^{\circ} 8 .^{\circ} \mathrm{da}$ primitiva Introdução ao nosso Código Civil) e de observar, aliás, a regra de direito internacional, acolhida tanto no Código Bustamante, como, já anteriormente, na Conferência de Haya.

Assim, na ação, em que os cônjuges se tiverem de empenhar (pois tudo leva a crer que o desquite seja litigioso), o juiz deve considerar o imóvel no Uruguai como pertencente ao casal, para o efeito de ser incluído no monte partível.

Precavendo-se contra as complicações que possam, eventualmente, surgir no Uruguai, com base num diverso critério acêrca do dito problema de direito internacional privado, cumpre, prudentemente, ao juiz brasileiro, ao deliberar a partilha, imputar, no quinhão meeiro do marido, o referido imóvel do Estado Oriental, dando-lhe sôbre os bens situados no Brasil, o que fôr necessário para completar a sua meação. Se não houver, no nosso país, bens suficientes para perfazer a meação da mulher, o marido será condenado a repor, a benefício daquela, o necessário valor. Por via de reposição em dinheiro, também seria resolvido o caso de não haver, no Brasil, quaisquer bens de comunhão. A ação de cobrança, correspondente à obrigação de realizar tais reposições, poderia, de futuro, se tornar ùtilmente possível.

Figuremos, entretanto, a hipótese de que o juiz brasileiro, a despeito das presentes sugestões, entendesse de incluir, no todo ou em parte, o imóvel do Uruguai na meação da mulher, formando o quinhão do marido, no todo ou em parte, com bens ou valores existentes no Brasil. 
Imaginemos, mais, que tal partilha não pudesse ser homologada ou executada no Uruguai, exatamente pelo fato de ter atribuído à mulher, total ou parcialmente, um imóvel considerado naquele país como estranho à comunhão conjugal.

Neste caso, parece que a mulher teria, contra o marido, a ação de que trata o art. $^{\circ} 1.802$ do Código Civil. O obstáculo, decorrente daquela atitude da justiça uruguaia, corresponderia pràticamente à evicção.

Enfim, - tendo sempre em vista o objetivo de fazer prevalecer, na espécie, o preceito do art. $8^{\circ}$ da primitiva Lei de Introdução ao Código Civil, o juiz deliberará a partilha, guardado o critério recomendado pelos art. $^{\circ}$ S $4 .^{\circ}$ e $5 .^{\circ}$ da atual Lei de Introdução. sulta.

O que vai acima exposto, responde aos quatro quesitos da con-

Em resumo, e reportando-nos, em seguida, a cada um dêles, somos de parecer:

1) - que, em face do direito brasileiro, é o regime da comunhão universal o existente entre os dois cônjuges aludidos na exposição;

2) - que, em face do direito brasileiro, o imóvel situado no Uruguai não está excluído da comunhão;

3) - que, mesmo perante o direito do Uruguai, segundo a interpretação que lhe dá uma autorizada corrente de doutrina e de jurisprudência dêsse país, o regime de bens do casal, aludido na consulta, é o da comunhão universal, com efeitos, também, sôbre o imóvel situado na vizinha república;

4) - que o juiz brasileiro, na previsão das dificuldades que possam surgir por parte da justiça uruguaia, outra cousa não tem a fazer do que adaptar a partilha às sugestões expostas acima.

E' o que pensamos, salvo melhor juizo.

NOTA A tese, sustentada neste parecer, já foi, há mais de 70 anos, ruidosamente debatida no Rio Grande do Sul, a propósito de uma acáo rescisória de partilha, ajuizado em Santa Vitoria do Palmar, por Nicolát Rodrigues de Lima e sua mulher contra os Alegre, em cofirmaño de do Desembargador Martins Costa, que as justicas do Império nă contra o voto, aliás, para decidir, por via de partilhas ou por outro qualquer modo, sôbre bens empetência

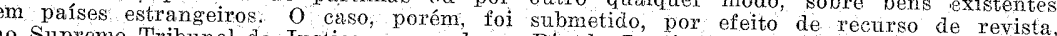
de 1.0 de maio de 1880 dę̧rovimento no Rio de Janeiro, o qual, por acórdão unânime do Des. Martins Costa, o tópico culminante dêsse aresto dassim, triunfar aquele voto do Império, está assim concebido: "Tendo sido a recorrida casada com o finado Comeria a costume do Império e, consequentemente, com comunhañ mandando 0 juiz situados no Estado Oriental, não excedia os limites do sua jupertencentes à recorrida, maria com o disposto na citada ord. liv. 4, tit. $96, \& 17$, devendo, sim, como se praticou a purtiha amigavel a fis., aquinhoar com aqueles, bens a mesma recorrida, para que ver conflito com assim, qualDr. João José do Monte - vol. 21, págos. 574 a

"SUPOSTA A EMISSÃO DE AÇÕES COM ÁGIO - NA HIPÓTESE DE AUMENTO DE CAPITAL DE SOCIEDADE BANCÁRIA, - DEVE ENTENDER-SE A IMPORTÂNCIA DO ÁGIO, QUANDO DESTINADA E INCORPORADA AO FUNDO DE RESERVA, COMO SUJEITA AO IMPÔSTO SÔBRE A RENDA E, POR VIA DE CONSEQÜENECIA, AO IMPÔSTO SÔBRE LUCROS EXTRAORDINÁRIOS?"

\section{Walter Carlos E. Becker}

\section{RESPOSTA:}

1. - Porque também no ato nulo há conteúdo econômico, passível de tributação $\left({ }^{1}\right)$, é aqui despicienda a controvérsia existente, na doutrina brasileira, sôbre a questão de saber se o decreto-lei n..$^{\circ} 2.627$ (Sociedades por Ações) de 26 de setembro de 1940, permite a emissão de ações com ágio $\left({ }^{2}\right)$.

2. - A tributabilidade (impôsto de renda) do ágio das ações depende da natureza que se reconhecer a êsse ágio. Muito se discute em tôrno dela $\left({ }^{3}\right)$.

(1) E. VANONI. Natura ed Interpretazioni Delle Leggi Tributarie, pág. 137.

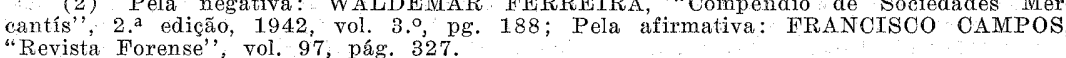

(3) Apud SOPRANO, Trattato delle Società Commerciale, vol. 1.०, pág. 479: RIC CARDI, Riv. dir dir. publ., 1910; 11, 189192, GOBBl, Mon. dei tribunali, 1910, 41 MANARA, Riv. di dir. comm., 1908, II, 531, e 1909, 1, 128; e in Foro italiano, 1911, DE GREGORIO, Riv, di Dir. comm., 1908, 1,301 e segg.; BONELLI, ivi, 1909, I, 833 GRAZIANI (Augusto) Dir. e giur., 1910, 284; OHTRONI, Riv. di diritto comm. 1910, 74, e 1912, 973, CHIRON, II soprarezzo, ece, TOESCA DI OASTELLAZZO, Dir. Finan 